\title{
Pre-treatment neutrophil-to-lymphocyte ratio may be associated with the outcome in patients treated with everolimus for metastatic renal cell carcinoma
}

\author{
M Santoni ${ }^{\star}, 1$, U De Giorgi ${ }^{2}$, R lacovelli ${ }^{3}$, A Conti ${ }^{4}$, L Burattini ${ }^{1}$, L Rossi ${ }^{2}$, S Luca Burgio ${ }^{2}$, R Berardi ${ }^{1}$, \\ G Muzzonigro ${ }^{4}$, E Cortesi ${ }^{3}, \mathrm{D}$ Amadori $^{2}$ and S Cascinu ${ }^{1}$ \\ ${ }^{1}$ Clinica di Oncologia Medica, AOU 'Ospedali Riuniti', Università Politecnica delle Marche, Via Tronto 10/A, 60126 Ancona, Italy; \\ ${ }^{2}$ Istituto Scientifico Romagnolo per lo Studio e la Cura dei Tumori-IRST, Via Piero Maroncelli 40, 47014 Meldola (FC), Italy; \\ ${ }^{3}$ Dipartimento di Scienze Radiologiche, Oncologiche e Anatomo-Patologiche, 'Sapienza' Università di Roma, piazzale Aldo Moro 5, \\ 00185 Rome, Italy and ${ }^{4}$ Dipartimento di Scienze Cliniche Specialistiche ed Odontostomatologiche, Clinica di Urologia, AOU \\ 'Ospedali Riuniti', Università Politecnica delle Marche, Via Tronto 10/A, 60126 Ancona, Italy
}

Background: Everolimus is a mammalian target of rapamycin inhibitor approved for the treatment of metastatic renal cell carcinoma (mRCC). We aimed to assess the association between pre-treatment neutrophil-to-lymphocyte ratio (NLR) and the outcome of patients treated with everolimus for mRCC.

Methods: Ninety-seven patients with mRCC were treated with everolimus till April 2013 in our institutions. Patients were stratified in two groups with NLR $>3$ (Group A) vs $<3$ (Group B). Progression-free survival (PFS) and overall survival (OS) were estimated using Kaplan-Meier method. Gender, age, Motzer prognostic group, PFS on first-line therapy, neutrophilia and NLR were included in the Cox analysis to investigate their prognostic relevance.

Results: Median OS and PFS were 10.6 and 5.3 months, respectively. Median OS was 12.2 months in Group A and 24.4 months in Group B $(P=0.001)$. Median PFS was 3.4 months in Group A and 9.9 months in Group B $(P<0.001)$. At multivariate analysis, only Motzer prognostic group and NLR were independent prognostic factors for OS and PFS

Conclusion: Pre-treatment NLR is an independent prognostic factor for patients with mRCC treated with second- or third-line everolimus. This should be investigated and validated in prospective studies.

In recent years, exciting advances have emerged in the treatment of metastatic renal cell carcinoma (mRCC), with the development of targeted agents in addition to immunotherapy-based treatments. This has been achieved primarily through the elucidation of the crucial role of vascular endothelial growth factor (VEGF) and mammalian target of rapamycin (mTOR) pathways in RCC. However, there is still a great deal of information to be discovered regarding the pathogenesis of this tumour. Increasing evidence suggests that inflammatory cells are an essential component of the tumour microenvironment and have a role in tumour progression (Mantovani et al, 2008; Hanahan and Weinberg, 2011). Tumour cells often constitutively produce several inflammatory chemokines, including neutrophil-attracting CXC-chemokines (Mantovani et al, 2008). The process of myelopoiesis is profoundly modified during inflammation and cancer, and this leads to the appearance of altered mature myelocytes and myeloid-derived 
suppressor cells, which account for immune suppression in patients with RCC (Mantovani et al, 2011).

Markers of inflammation, such as the neutrophil-to-lymphocyte ratio (NLR), and their clinical significance in RCC patients are still under evaluation. NLR is an easily measurable parameter of systemic inflammation. Increased pre-treatment NLR has been demonstrated to be associated with poor outcome for various types of cancers, including gastric cancer (Yamanaka et al, 2007), advanced pancreatic cancer (An et al, 2010), hepatocellular carcinoma (Gomez et al, 2008), colorectal liver metastases (Kishi et al, 2009), non-small-cell lung cancer (Sarraf et al, 2009), malignant mesothelioma (Kao et al, 2010), ovarian cancer (Cho et al, 2009) and soft-tissue sarcoma (Szkandera et al, 2013). However, to our knowledge, we are the first to investigate the association between pre-treatment NLR and outcome of mRCC patients treated with mTOR inhibitor everolimus as second- or third-line therapy.

The mTOR signalling pathway is crucial for a wide variety of cells including leukocytes, and dysfunction within the mTOR axis may have a role in the pathogenesis of RCC (Thomas et al, 2006). Based on the results of the phase III RECORD-1 trial (Motzer et al, 2008,2010 ), everolimus, a potent mTOR inhibitor, has become the recommended standard of care for patients with mRCC whose disease has progressed after initial TKI therapy (de Reijke et al, 2009; Ljungberg et al, 2010).

To our knowledge, no study to date has validated molecular predictive and prognostic markers associated with outcome of mRCC patients treated with mTOR inhibitors. In the present study, we aimed at further assessing the prognostic significance of pre-treatment NLR in patients receiving everolimus as second- and third-line therapy for mRCC.

\section{MATERIALS AND METHODS}

Patients. The study population consisted of adults (aged 18 years and above) with metastatic clear cell RCC, treated with everolimus after failure of initial one or two TKIs. Treatments were separated by a wash-out period of at least 2 weeks. Patients were treated in three Italian Institutions between January 2005 and April 2013. Data were retrospectively collected from patient's electronic medical records and paper charts.

Patients were ineligible if they had previously received mTOR inhibitor therapy (temsirolimus) or if they presented factors that could influence NLR, such as concurrent infections, chronic inflammatory diseases or recent treatment with steroids.

Peripheral blood samples were obtained 1-7 days before the start of everolimus. Patients without available data on pretreatment NLR and those with baseline comorbidity such as chronic lymphocytic leukemia, chronic inflammatory diseases, previous treatment with mTOR inhibitor temsirolimus and recent therapy with steroids, cytokines or granulocyte colony-stimulating factor were excluded from this analysis.

Treatment regimens and statistical analysis. Everolimus was administered orally, usually at a starting dose of $10 \mathrm{mg}$ once daily. In patients with significant comorbidities, treatment was initiated at a reduced dose, with subsequent dose escalation if well tolerated. On treatment, dose reductions or treatment interruptions were done for the management of adverse events, depending on their type and severity, according to standard guidelines. Treatment was continued until evidence of disease progression on scans, unacceptable adverse events or death. Follow-up generally consisted of regular physical examination and laboratory assessment (haematologic and serum chemical measurements), every 4-6 weeks, and imaging studies by computed tomography or magnetic resonance imaging scans were carried out according to local procedures every 8-12 weeks. The progression of disease was defined as $a \geqslant 20 \%$ increase of the long diameter according to the RECIST 1.0 criteria (Therasse et al, 2000). Values were expressed as median and interquartile range. Progression-free survival (PFS) was defined as the time from beginning of treatment to progression or to death from any cause, whichever occurred first. Patients without tumour progression or death at the time of the data cutoff for the analysis or at the time of receiving an additional anticancer therapy were censored at their last date of adequate tumour evaluation. PFS and overall survival (OS) were estimated using Kaplan-Meier method with Rothman's 95\% confidence intervals (CIs) and compared across the groups using the log-rank test. Patients with a stable disease, partial remission and a complete remission were considered as responders.

Pre-treatment NLR was calculated by dividing the absolute neutrophil count by the absolute lymphocyte count and potential factors associated with outcome were evaluated, including patients' gender, age, Motzer prognostic group, PFS on first-line therapy, neutrophilia and NLR. The value of NLR that best discriminated between good and poor survival, which is with the most significant $P$-value according to the log-rank test, was determined by testing all possible cutoffs.

Cox proportional hazard models were applied to explore patients' characteristics predictors of survival in univariate- and multivariable-adjusted analysis using a stepwise selection approach with type I error of 0.05 for model entry and 0.10 for elimination. Additional elimination was applied to identify significant variables at the level of $P<0.05$. All statistical analysis was done using MedCalc version 11.4.4.0 (MedCalc Software, Broekstraat 52, 9030, Mariakerke, Belgium).

The research was carried out in accordance with the approval by the ethical committee of our institution.

\section{RESULTS}

One hundred and seven patients received everolimus till April 2013 in our institutions. Of these, 97 patients (70 males and 27 females) were included in the NLR analysis, whereas 10 patients were excluded for the lack of data on pre-treatment NLR. Median age was 64 years $(95 \% \mathrm{CI}=44-82)$. Patients' characteristics are summarised in Table 1. Median follow-up time from diagnosis was 46.9 months $(95 \% \mathrm{CI}=39.9-53.9)$. Thirty-nine patients died during their follow-up.

Twenty-three percent of patients were at favourable risk, $67 \%$ at intermediate risk and $10 \%$ at poor risk. When stratified by previous therapy, 67\% $(n=65)$ of patients had received one previous VEGFR-TKI and 33\% $(n=32)$ of patients had received two previous VEGFR-TKIs. The distribution of sequences is reported in Table 1.

Median neutrophil count was 3620 per $\mathrm{mm}^{3}$, median lymphocyte count was 1480 per $\mathrm{mm}^{3}$ and median NLR was 2.2. When NLR was analysed as a dichotomous variable, a cut-point of 3 provided the strongest prognostic value in our data set, therefore, this level was chosen for further study. Patients were further divided depending on NLR into two groups. Thirty-eight patients (40\%) had NLR >3 at baseline (Group A), whereas 59 had lower NLR (Group B). In Group A, 15 patients had absolute neutrophilia (defined as $>7500$ per $\mathrm{mm}^{3}$ in our institutions). Baseline characteristics and therapy sequences did not significantly differ according to groups: thus in Group A, 25 patients (66\%) received everolimus as second line and $13(34 \%)$ as third line, whereas in Group B, 40 patients (68\%) received everolimus as second line and $19(32 \%)$ as third line.

Median OS from everolimus was 10.6 months (95\% CI $=7.8-13.4$ ) and median PFS was 5.3 months $(95 \% \mathrm{CI}=4.4-6.2)$. Median OS 
was 12.2 months $(95 \% \mathrm{CI}=10.1-14.3)$ in Group A and 24.4 months $(95 \% \mathrm{CI}=20.9-27.9)$ in Group B $(P=0.001$; Figure $1 \mathrm{~A})$. Median PFS was 3.4 months $(95 \% \mathrm{CI}=2.6-4.2)$ in Group A and 9.9 months $(7.8-12.0)$ in Group B $(P<0.001$; Figure 1B). The

\begin{tabular}{|c|c|}
\hline Patients & $97(\%)$ \\
\hline \multicolumn{2}{|l|}{ Gender } \\
\hline Male & $70(72 \%)$ \\
\hline Female & $27(28 \%)$ \\
\hline Age, years & 64 \\
\hline Range & $44-82$ \\
\hline \multicolumn{2}{|l|}{ Karnofsky performance status } \\
\hline Score $>70$ & $90(93 \%)$ \\
\hline Score $<70$ & 7 (7\%) \\
\hline Past nephrectomy & $91(94 \%)$ \\
\hline \multicolumn{2}{|l|}{ Motzer risk stratification } \\
\hline Favourable risk & $22(23 \%)$ \\
\hline Intermediate risk & $65(67 \%)$ \\
\hline Poor risk & $10(10 \%)$ \\
\hline \multicolumn{2}{|l|}{ Common sites of metastasis } \\
\hline Lymph nodes & $43(44 \%)$ \\
\hline Lung & 75 (77\%) \\
\hline Bone & 33 (34\%) \\
\hline Liver & $18(19 \%)$ \\
\hline $\begin{array}{l}\text { Patients treated with second-line } \\
\text { everolimus }\end{array}$ & 65 \\
\hline Sunitinib_-everolimus & $54(83 \%)$ \\
\hline Sorafenib—everolimus & $3(5 \%)$ \\
\hline Pazopanib_everolimus & $8(12 \%)$ \\
\hline $\begin{array}{l}\text { Patients treated with third-line } \\
\text { everolimus }\end{array}$ & 32 \\
\hline Sunitinib_-sorafenib_everolimus & $19(59 \%)$ \\
\hline Sorafenib_-sunitinib_everolimus & 9 (28\%) \\
\hline $\begin{array}{l}\text { Bevacizumab + IFN- } \alpha \text {-sunitinib- } \\
\text { everolimus }\end{array}$ & $4(13 \%)$ \\
\hline Median neutrophil count & 3620 per $\mathrm{mm}^{3}$ \\
\hline Median lymphocyte count & 1480 per $\mathrm{mm}^{3}$ \\
\hline \multicolumn{2}{|l|}{ Neutrophil-to-lymphocyte ratio } \\
\hline Score $>3$ & $38(39 \%)$ \\
\hline Score $<3$ & $59(61 \%)$ \\
\hline
\end{tabular}

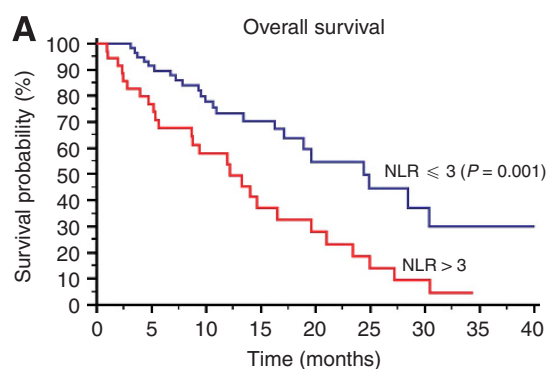

relative risk of progression within 6 months from the start of everolimus in Group A vs Group B was 1.61 (95\% CI = 1.13 to 2.29).

Univariate analysis showed that Motzer prognostic group $(\mathrm{HR}=1.84 ; \quad 95 \% \quad \mathrm{CI}=1.10-3.08 ; \quad P=0.02), \quad$ neutrophilia $(\mathrm{HR}=2.73 ; 95 \% \mathrm{CI}=1.50-4.95 ; P=0.001)$ and $\mathrm{NLR}(\mathrm{HR}=2.99$; 95\% $\mathrm{CI}=1.80-4.97 ; \quad P<0.001)$ were associated with $\mathrm{PFS}$. At multivariate analysis, only Motzer prognostic group $(\mathrm{HR}=1.93 ; 95 \% \mathrm{CI}=1.15-3.23 ; P=0.013)$ and $\mathrm{NLR}(\mathrm{HR}=2.66$; 95\% CI $=1.43-4.94 ; P=0.002$ ) were predictors of PFS.

As for OS, univariate analysis showed that Motzer prognostic group $(\mathrm{HR}=2.54 ; 95 \% \mathrm{CI}=1.36-4.76 ; P=0.004)$, neutrophilia $(\mathrm{HR}=2.08 ; 95 \% \mathrm{CI}=1.08-3.99 ; P=0.02)$ and $\mathrm{NLR}(\mathrm{HR}=2.45$; $95 \% \mathrm{CI}=1.40-4.30 ; P=0.002)$ were associated with OS. Multivariate Cox regression analysis revealed that only Motzer prognostic group $(\mathrm{HR}=2.96 ; 95 \% \mathrm{CI}=1.57-5.57 ; P<0.001)$ and NLR (HR $=2.27 ; 95 \% \mathrm{CI}=1.16-4.30 ; P=0.003)$ were independent prognostic factors (Table 2).

\section{DISCUSSION}

RCC is considered to be an immunogenic tumour (Tsavaris et al, 1996). This evidence is based on several reports, such as the incidence of spontaneous regressions observed in a small number of these patients (De Riese et al, 1991) and its response rate to immunotherapy (Alexandrescu and Dasanu, 2006; Motzer and Bukowski, 2006; Yang and Childs, 2006), such as high-dose IL-2, suggesting that host immune response to RCC has a role in the disease control.

However, based on the complexity of the interaction between tumour and host immune responses, there is still a great deal of information to be discovered both on the effects of targeted agents on immune system and, otherwise, on the role of immune cells in tumour response to targeted therapies (Santoni et al, 2012). In 2009, Jensen et al (2009) observed that the presence of intratumour neutrophils is an independent prognostic factors for short recurrence-free and OS in localised clear cell RCC. In the Heng prognostic model, increased blood neutrophil count was significantly associated with poor prognosis in mRCC patients (Heng et al, 2009), but not unanimously in other studies (Patil et al, 2011). This may be partially explained by the potential parallel role of lymphocyte-mediated immune response, which has not been taken into account.

These data suggest that NLR may reflect the contribution of immune response on RCC progression and response to treatment, representing a better predictor of outcome. Moreover, the controversial association between blood neutrophil count and RCC development and progression has not considered the existence of different neutrophil subsets (Beyrau et al, 2012), identified through expression of specific molecular markers, and their different functional capacities, which have not been elucidated yet in RCC.

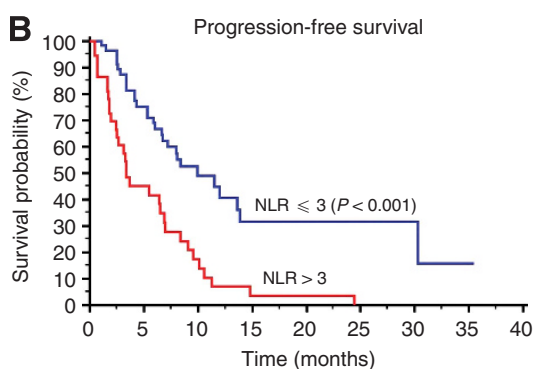

Figure 1. OS (A) and PFS (B) in patients treated with everolimus for $\mathrm{mRCC}$. 
Table 2. Univariate and multivariable analysis of predictors of PFS and OS of patients treated with everolimus for mRCC

\begin{tabular}{|c|c|c|c|c|}
\hline & \multicolumn{2}{|c|}{ Univariate Cox regression } & \multicolumn{2}{|c|}{ Multivariable Cox regression } \\
\hline & $\mathrm{HR}(95 \% \mathrm{Cl})$ & $P$-value & $\mathrm{HR}(95 \% \mathrm{Cl})$ & $P$-value \\
\hline \multicolumn{5}{|l|}{ PFS } \\
\hline $\begin{array}{l}\text { Gender } \\
\text { Age } \\
\text { Motzer prognostic group } \\
\text { PFS on first-line therapy } \\
\text { Neutrophilia }(\mathrm{Y} / \mathrm{N}) \\
\text { NLR }>3 \text { vs }<3\end{array}$ & $\begin{array}{l}0.67(0.45-1.33) \\
1.00(0.98-1.02) \\
1.84(1.10-3.08) \\
1.21(0.69-2.12) \\
2.73(1.50-4.95) \\
2.99(1.80-4.97)\end{array}$ & $\begin{array}{c}0.36 \\
0.89 \\
0.02 \\
0.50 \\
0.001 \\
<0.001\end{array}$ & $\begin{array}{l}1.93(1.15-3.23) \\
2.66(1.43-4.94)\end{array}$ & 0.013 \\
\hline \multicolumn{5}{|l|}{ OS } \\
\hline $\begin{array}{l}\text { Gender } \\
\text { Age } \\
\text { Motzer prognostic group } \\
\text { PFS on first-line therapy } \\
\text { Neutrophilia (Y/N) } \\
\text { NLR }>3 \text { vs }<3\end{array}$ & $\begin{array}{l}0.85(0.45-1.60) \\
0.98(0.95-1.00) \\
2.54(1.36-4.76) \\
1.08(0.57-2.03) \\
2.08(1.08-3.99) \\
2.45(1.40-4.30)\end{array}$ & $\begin{array}{l}0.63 \\
0.16 \\
0.004 \\
0.322 \\
0.02 \\
<0.001\end{array}$ & $\begin{array}{l}2.96(1.57-5.57) \\
2.27(1.16-4.43)\end{array}$ & $<0.001$ \\
\hline
\end{tabular}

Previous groups have examined pretreatment NLR in RCC patients. Ohno et al $(2010,2012)$ have demonstrated the prognostic role of pre- and post-treatment NLR in non-metastatic and mRCC who underwent radical nephrectomy and the association between post-operative NLR and recurrence-free survival. In 2012, Keizman et al (2012) has published the results of a retrospective analysis in mRCC patients treated with sunitinib as first-line therapy. In this study, low NLR $\leqslant 3(\mathrm{HR}=0.285, P<0.001)$, past nephrectomy $(\mathrm{HR}=0.38, P=0.035)$, sunitinib dose reduction/treatment interruption $(\mathrm{HR}=0.6, P=0.014)$ and the use of angiotensin system inhibitors ( $\mathrm{HR}=0.537, P=0.008)$ were significantly associated with PFS, whereas low NLR $\leqslant 3$ was associated with OS $(\mathrm{HR}=0.3$, $P=0.043$ ). In 2013, NLR has been validated as prognostic factor in non-metastatic clear cell RCC patients (Pichler et al, 2013). Recently, Kobayashi et al (2013) revealed that changes in NLR during the early phase of targeted therapy may be a powerful discriminator of who will benefit from the subsequent treatment with molecular-targeted therapy. They observed that Th1/Th2 ratio was not associated with PFS in any targeted therapy, whereas lower pre-treatment NLR was associated with longer PFS in 58 patients treated with sorafenib, sunitinib, everolimus or temsirolimus (Kobayashi et al, 2013).

In our study, we first demonstrate that increased pre-treatment NLR was significantly associated with worse PFS and OS in the overall population and in the cohorts of patients treated with second- or third-line everolimus after VEGFR-TKI therapy. At multivariate analysis, neutrophilia was not an independent prognostic factor for PFS and OS, whereas the prognostic role of Motzer prognostic group and NLR were confirmed. Differently from previous studies, PFS on first-line therapy did not result an independent prognostic factor for OS (Iacovelli et al, 2013).

However, there are some limitations to this study. First, this is a retrospective study, which is susceptible to bias in data selection and analysis. The total number of patients analysed is relatively small and not included patients with non-clear cell RCC. Other inflammatory markers, such as procalcitonin or CRP, which has demonstrated to be an independent prognostic factor in patients with RCC (Steffens et al, 2012; de Martino et al, 2013), are not routinely measured in our institutions. Also, NLR differs among individuals and can be influenced by concurrent infection and drugs that cannot be accounted for in this study.
Despite these limitations, our study suggests that pre-treatment NLR may be associated with PFS and OS of patients treated with everolimus for mRCC and should be introduced in clinical practice. Prospective studies are needed to determine the immunogenic mechanisms underlying NLR variations and to adequately assess the potential role of NLR in guiding treatment decisions, patient selection and clinical trials design.

\section{ACKNOWLEDGEMENTS}

Sincere gratitude is owned to Professor Alberto Mantovani for his support throughout this work.

\section{CONFLICT OF INTEREST}

The authors declare no conflict of interest.

\section{REFERENCES}

Alexandrescu DT, Dasanu CA (2006) Kidney cancer therapy: new perspectives and avenues. Expert Opin Pharmacother 7: 2481-2493.

An X, Ding PR, Li YH, Wang FH, Shi YX, Wang ZQ, He YJ, Xu RH, Jiang WQ (2010) Elevated neutrophil to lymphocyte ratio predicts survival in advanced pancreatic cancer. Biomarkers 15: 516-522.

Beyrau M, Bodkin JV, Nourshargh S (2012) Neutrophil heterogeneity in health and disease: a revitalized avenue in inflammation and immunity. Open Biol 2: 120134.

Cho H, Hur HW, Kim SW, Kim SH, Kim JH, Kim YT, Lee K (2009) Pre-treatment neutrophil to lymphocyte ratio is elevated in epithelial ovarian cancer and predicts survival after treatment. Cancer Immunol Immunother 58: 15-23.

de Martino M, Klatte T, Seemann C, Waldert M, Haitel A, Schatzl G, Remzi M, Weibl P (2013) Validation of serum C-reactive protein (CRP) as an independent prognostic factor for disease-free survival in patients with localised renal cell carcinoma (RCC). BJU Int 111: E348-E353.

de Reijke TM, Bellmunt J, van Poppel H, Marreaud S, Aapro M (2009) EORTC-GU group expert opinion on metastatic renal cell cancer. Eur J Cancer 45: 765-773. 
De Riese W, Goldenberg K, Allhoff E, Jonas U (1991) Spontaneous regression of metastatic renal carcinoma with long-term survival. Br J Urol 68: 98-100.

Gomez D, Farid S, Malik HZ, Young AL, Toogood GJ, Lodge JP, Prasad KR (2008) Preoperative neutrophil-to-lymphocyte ratio as a prognostic predictor after curative resection for hepatocellular carcinoma. World J Surg 32: 1757-1762.

Hanahan D, Weinberg RA (2011) Hallmarks of cancer: the next generation. Cell 144: 646-674.

Heng DY, Xie W, Regan M, Warren MA, Golshayan AR, Sahi C, Eigl BJ, Ruether JD, Cheng T, North S, Venner P, Knox JJ, Chi KN,

Kollmannsberger C, McDermott DF, Oh WK, Atkins MB, Bukowski RM, Rini BI, Choueiri TK (2009) Prognostic factors for overall survival in patients with metastatic renal cell carcinoma treated with vascular endothelial growth factor-targeted agents: results from a large, multicenter study. J Clin Oncol 27: 5794-5799.

Iacovelli R, Carteni G, Sternberg CN, Milella M, Santoni M, Di Lorenzo G, Ortega C, Sabbatini R, Ricotta R, Messina C, Lorusso V, Atzori F, De Vincenzo F, Sacco C, Boccardo F, Valduga F, Massari F, Baldazzi V, Cinieri S, Mosca A, Ruggeri EM, Berruti A, Cerbone L, Procopio G (2013) Clinical outcomes in patients receiving three lines of targeted therapy for metastatic renal cell carcinoma: results from a large patient cohort. Eur J Cancer; 49: 2134-2142.

Jensen HK, Donskov F, Marcussen N, Nordsmark M, Lundbeck F, von der Maase H (2009) Presence of intratumoral neutrophils is an independent prognostic factor in localized renal cell carcinoma. J Clin Oncol 27: 4709-4717.

Kao SC, Pavlakis N, Harvie R, Vardy JL, Boyer MJ, van Zandwijk N, Clarke SJ (2010) High blood neutrophil-to-lymphocyte ratio is an indicator of poor prognosis in malignant mesothelioma patients undergoing systemic therapy. Clin Cancer Res 16: 5805-5813.

Keizman D, Ish-Shalom M, Huang P, Eisenberger MA, Pili R, Hammers H, Carducci MA (2012) The association of pre-treatment neutrophil to lymphocyte ratio with response rate, progression free survival and overall survival of patients treated with sunitinib for metastatic renal cell carcinoma. Eur J Cancer 48: 202-208.

Kishi Y, Kopetz S, Chun YS, Palavecino M, Abdalla EK, Vauthey JN (2009) Blood neutrophil-to-lymphocyte ratio predicts survival in patients with colorectal liver metastases treated with systemic chemotherapy. Ann Surg Oncol 16: 614-622.

Kobayashi M, Kubo T, Komatsu K, Fujisaki A, Terauchi F, Natsui S, Nukui A, Kurokawa S, Morita T (2013) Changes in peripheral blood immune cells: their prognostic significance in metastatic renal cell carcinoma patients treated with molecular targeted therapy. Med Oncol 30: 556.

Ljungberg B, Cowan NC, Hanbury DC, Hora M, Kuczyk MA, Merseburger AS, Patard JJ, Mulders PF, Sinescu IC. European Association of Urology Guideline Group (2010) EAU guidelines on renal cell carcinoma: the 2010 update. Eur Urol 58: 398-406.

Mantovani A, Allavena P, Sica A, Balkwill F (2008) Cancer-related inflammation. Nature 454: 436-444.

Mantovani A, Cassatella MA, Costantini C, Jaillon S (2011) Neutrophils in the activation and regulation of innate and adaptive immunity. Nat Rev Immunol 11: 519-531.

Motzer RJ, Bukowski RM (2006) Targeted therapy for metastatic renal cell carcinoma. J Clin Oncol 24: 5601-5608.

Motzer RJ, Escudier B, Oudard S, Hutson TE, Porta C, Bracarda S, Grünwald V, Thompson JA, Figlin RA, Hollaender N, Urbanowitz G, Berg WJ, Kay A, Lebwohl D, Ravaud A. RECORD-1 Study Group (2008) Efficacy of everolimus in advanced renal cell carcinoma: a double-blind, randomised, placebo-controlled phase III trial. Lancet 372: 449-456.
Motzer RJ, Escudier B, Oudard S, Hutson TE, Porta C, Bracarda S, Grünwald V, Thompson JA, Figlin RA, Hollaender N, Kay A, Ravaud A. RECORD-1 Study Group (2010) Phase 3 trial of everolimus for metastatic renal cell carcinoma: final results and analysis of prognostic factors. Cancer 116: 4256-4265.

Ohno Y, Nakashima J, Ohori M, Gondo T, Hatano T, Tachibana M (2012) Follow up of neutrophil-to-lymphocyte ratio and recurrence of clear cell renal cell carcinoma. J Urol 187: 411-417.

Ohno Y, Nakashima J, Ohori M, Hatano T, Tachibana M (2010) Pretreatment neutrophil-to-lymphocyte ratio as an independent predictor of recurrence in patients with non-metastatic renal cell carcinoma. J Urol 184: 873-878.

Patil S, Figlin RA, Hutson TE, Michaelson MD, Négrier S, Kim ST, Huang X, Motzer RJ (2011) Prognostic factors for progression-free and overall survival with sunitinib targeted therapy and with cytokine as first-line therapy in patients with metastatic renal cell carcinoma. Ann Oncol 22: 295-300.

Pichler M, Hutterer GC, Stoeckigt C, Chromecki TF, Stojakovic T, Golbeck S, Eberhard K, Gerger A, Mannweiler S, Pummer K, Zigeuner R (2013) Validation of the pre-treatment neutrophil lymphocyte ratio as a prognostic factor in a large European cohort of renal cell carcinoma patients. Br J Cancer 108: 901-907.

Santoni M, Rizzo M, Burattini L, Farfariello V, Berardi R, Santoni G, Cascinu S (2012) Present and future of tyrosine kinase inhibitors in renal cell carcinoma: analysis of hematologic toxicity. Recent Pat Antinfect Drug Discov 7: 104-110.

Sarraf KM, Belcher E, Raevsky E, Nicholson AG, Goldstraw P, Lim E (2009) Neutrophil/lymphocyte ratio and its association with survival after complete resection in non-small cell lung cancer. J Thorac Cardiovasc Surg 137: 425-428.

Steffens S, Köhler A, Rudolph R, Eggers H, Seidel C, Janssen M, Wegener G, Schrader M, Kuczyk MA, Schrader AJ (2012) Validation of CRP as prognostic marker for renal cell carcinoma in a large series of patients. BMC Cancer 12: 399.

Szkandera J, Absenger G, Liegl-Atzwanger B, Pichler M, Stotz M, Samonigg H, Glehr M, Zacherl M, Stojakovic T, Gerger A, Leithner A (2013) Elevated preoperative neutrophil/lymphocyte ratio is associated with poor prognosis in soft-tissue sarcoma patients. Br J Cancer 108: 1677-1683.

Therasse P, Arbuck SG, Eisenhauer EA, Wanders J, Kaplan RS, Rubinstein L, Verweij J, Van Glabbeke M, van Oosterom AT, Christian MC, Gwyther SG (2000) New guidelines to evaluate the response to treatment in solid tumors. European Organization for Research and Treatment of Cancer, National Cancer Institute of the United States, National Cancer Institute of Canada. J Natl Cancer Inst 92: 205-216.

Thomas GV, Tran C, Mellinghoff IK, Welsbie DS, Chan E, Fueger B, Czernin J, Sawyers CL (2006) Hypoxia-inducible factor determines sensitivity to inhibitors of mTOR in kidney cancer. Nat Med 12: 122-127.

Tsavaris N, Baxevanis C, Kosmidis P (1996) The prognostic significance of immune changes in patients with renal cell carcinoma, malignant melanoma and colorectal carcinoma treated with IFNalpha2b. Cancer Immunol Immunother 43: 94-104.

Yamanaka T, Matsumoto S, Teramukai S, Ishiwata R, Nagai Y, Fukushima M (2007) The baseline ratio of neutrophils to lymphocytes is associated with patient prognosis in advanced gastric cancer. Oncology 73: 215-220.

Yang JC, Childs R (2006) Immunotherapy for renal cell cancer. J Clin Oncol 24: 5576-5583.

This work is published under the standard license to publish agreement. After 12 months the work will become freely available and the license terms will switch to a Creative Commons AttributionNonCommercial-Share Alike 3.0 Unported License. 